\title{
INFLUENCE OF WEATHER FACTORS ON THE ABUNDANCE AND POPULATION DYNAMICS OF Spodoptera litura F. AND Pieris brassicae L. ON CABBAGE
}

\author{
M.M.H. Khan ${ }^{1 *}$ and S. Talukder ${ }^{2}$ \\ ${ }^{1}$ Department of Entomology, Patuakhali Science and Technology University, Dumki, Patuakhali-8602, \\ Bangladesh \\ ${ }^{2}$ Ispahani Mirzapur Tea Estate, Srimongal, Moulavibazar, Sylhet, Bangladesh
}

\begin{abstract}
In order to study the influence of weather factors on the abundance and population dynamics of Spodoptera litura F. and Pieris brassicae L. on cabbage, a field experiment was conducted. Larval population of $S$. litura ranged from 0.56 to 1.57 larvae/plant during 8 January to 12 February 2014 crop season while the highest peak was on 5 February 2014 (1.57 larvae/plant) at $29.5^{\circ} \mathrm{C}$ temperature. In case of Pieris brassicae, larval population ranged from 0.58 to1.98 larvae/plant and the highest peak of $P$. brassicae was also on 5 February. The highest peak was on 5 February 2014 at $96 \%$ and $38 \%$ relative humidity of both maximum and minimum categories and the highest peak of $P$. brassicae was on 5 February. There was a strong positive correlation $(r=0.824$ and $r=$ 0.920 ) between population of Spodoptera litura and temperature (maximum and minimum). On the other hand, there was a negative correlation $(r=-0.439)$ between population of $S$. litura and maximum relative humidity and a strong negative correlation $(r=-0.716)$ between population of $S$. litura and minimum relative humidity. The population of Pieris brassicae was positively correlated $(r=0.899$ and $r=0.956)$ with maximum and minimum temperatures. There was a negative correlation $(r=-0.443)$ between population of $P$. brassicae and maximum relative humidity and a strong negative correlation $(r=-0.645)$ between population of $P$. brassicae and minimum relative humidity.
\end{abstract}

Keywords: Cabbage, Spodoptera litura, Pieris brassicae, weather parameters

\section{INTRODUCTION}

Cabbage (Brassica oleracea L. var. capitata) is one of the most popular vegetables in the world as well as in Bangladesh. It is grown in winter and the

\footnotetext{
*Corresponding author: mohasin1965@pstu.ac.bd
}

Received: 25.11.2016 
annual production of cabbage is 217 thousand tons (BBS, 2014) in this country. The production and yield of cabbage is greatly hampered by several insect pests viz., cabbage butterfly (Pieris brassicae), diamond back moth (Plutella xylostella Linnaeus), tobacco caterpillar (Spodoptera litura Fabricius) and cabbage aphid (Brevicoryne brassicae L.). Out of these, cabbage butterfly, diamond back moth and tobacco caterpillar are the most destructive pests causing severe yield loss to cabbage every year (Rao and Lal, 2005; Mahla et al., 2005; Kumar et al., 2007). Cabbage butterfly ( $P$. brassicae) was recorded as serious pest of cabbage, cauliflower, kohlrabi, broccoli, brussels and sprouts in cauliflower growing areas of the world (Hasan and Ansari, 2011).

In Bangladesh, leaf eating caterpillars such as diamondback moth (DBM) and prodenia caterpillar or common cutworm (Spodoptera litura) are considered as the major pests of cabbage (Anonymous, 2013). After hatching, the caterpillars start feeding on the under surface of the leaves. Leaves of heavily damaged plants have many feeding holes and sometimes the leaves take a 'sieve-like' appearance. Larvae also bore into the newly formed head through reaching to the newly emerging little leaf and consume it. As a result of feeding, the plants either fail to form compact cabbage heads or produce deformed heads (Uddin et al., 2007). Though the agroclimatic condition of Bangladesh is highly favourable for the successful cultivation of cabbage, this has not yet translated into higher yield mainly due to the attack of insect pests. The severity of the abundance of different insect pests of cabbage is greatly influenced by the prevailing climatic conditions which vary from region to region, even place to place of the country. Therefore, up to date knowledge about the abundance pattern of major insect pests and their population dynamics on a particular crop is a prerequisite for the implementation of an effective and successful insect pest management programme against them. Keeping these views in mind, the present study was conducted to know the abundance and population dynamics of Spodoptera litura F. and Pieris brassicae L. on cabbage in relation to weather parameters.

\section{MATERIALS AND METHODS}

The field experiment was conducted at agricultural farm of Patuakhali Science and Technology University, Dumki, Patuakhali to study the influence of weather factors on the abundance and population dynamics of Spodoptera litura F. and Pieris brassicae L. on cabbage during rabi season of 2013-2014. Two cabbage varieties viz., Atlas $70\left(\mathrm{~V}_{1}\right)$ and Super tropic $\left(\mathrm{V}_{2}\right)$ were included in this study. Experiment was laid out in randomized block design (RBD) with three replications. The entire field was divided into three blocks and each block was again divided into ten plots. The distance between both blocks and plots was $1.0 \mathrm{~m}$. The area of each experimental 
plot was $9 \mathrm{~m}^{2}$. Seeds of the selected cultivars were sown in the month of November and were transplanted in December. Thirty day-old cabbage seedlings were transplanted in the plot of $9 \mathrm{~m}^{2}$ area with $45 \mathrm{~cm} \mathrm{x} 45 \mathrm{~cm}$ spacing on 29 December, 2013. The chemical fertilizers viz., urea, TSP and MP were applied at the rate of 285 , 145 and $218 \mathrm{~kg} \mathrm{ha}^{-1}$. Fertilizer, irrigate ion and all other agronomic practices were carried out in the experimental field as and when needed. All inputs for example fertilizer application, irrigation, hoeing and other agronomic practices remained same for all cultivars. Recommended management practices except plant protection measures were followed for raising the crop. Weekly observations were taken since one week of transplanting till maturity of the crop.

Observation on population dynamics of Spodoptera litura and Pieris brassicae started as soon as their infestation was noticed. Population density was determined on the basis of number of larvae per plant on randomly selected plants at weekly interval. All the open leaves and heads of the selected plants were observed thoroughly and the larvae found were recorded. Larvae of tobacco caterpillar and cabbage butterfly were counted from randomly selected 10 plants per replication.

Meteorological parameters (temperature and humidity) were collected from meteriological office of Patuakhali district and correlated with the population of tobacco caterpillar (Spodoptera litura) and cabbage butterfly (Pieris brassicae) through Microsoft Excel program.

\section{RESULTS AND DISCUSSION}

\section{Influence of temperature}

Trend of incidence of Spodoptera litura and Pieris brassicae on cabbage in relation to maimum and minimum temperature on different dates of observations is presented in figure 1. Larval population of $S$. litura ranged from 0.56 to1.57 larvae/plant during 8 January to 12 February 2014 crop season. S. litura was first noticed in the field on 8 January, 2014 (0.68 larvae/plant) with decreasing and increasing pattern which results fluctuation of population on remaining dates of observations. However, the highest peak was on 5 February 2014 (1.57 larvae/plant) at $29.5{ }^{\circ} \mathrm{C}$ temperature (Figure 1). In case of Pieris brassicae, larval population ranged from 0.58 to1.98 larvae/plant and more or less similar trend of population fluctuation was observed on various dates of observations. The highest peak of $P$. brassicae was also on 5 February (Figure 1). Maximum and minimum temperature had positive influence on population growth of both species. 


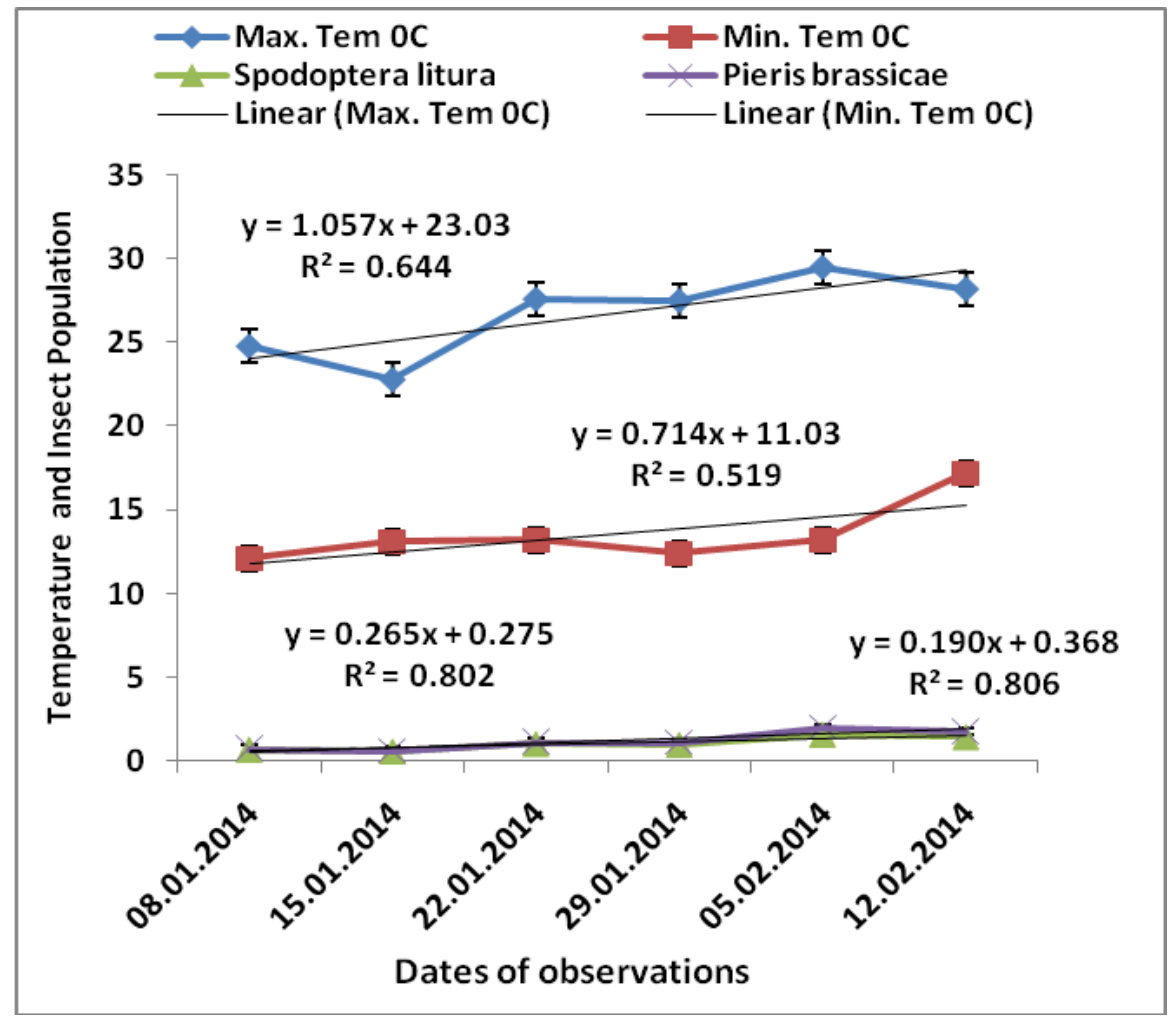

Figure 1. Trend of incidence of Spodoptera litura and Pieris brassicae on cabbage at different dates of observations as influenced by maximum and minimum temperature

\section{Influence of humidity}

Trend of incidence of Spodoptera litura and Pieris brassicae on cabbage in relation to maximum and minimum humidity on different dates of observations is presented in figure 2. Larval population of $S$. litura ranged from 0.56 to 1.57 larvae/plant during 8 January to 12 February 2014 crop season. The highest peak was on 5 February 2014 (1.57 larvae/plant) (Figure 2) at 96\% and 38\% relative humidity of both maximum and minimum categories. In case of Pieris brassicae, larval population ranged from 0.58 to 1.98 larvae/ plant and more or less similar trend of population fluctuation was observed on various dates of observations. Likewise, the highest peak of $P$. brassicae was on 5 February (Figure 2) at similar conditions of humidity. Maximum and minimum humidity had negative influence on population growth of both species. As incidence of pest depends on host suitability and climatic condition, therefore, incidence and peak infestation of pest vary from variety to variety and due to variation of management practices in cabbage field. 


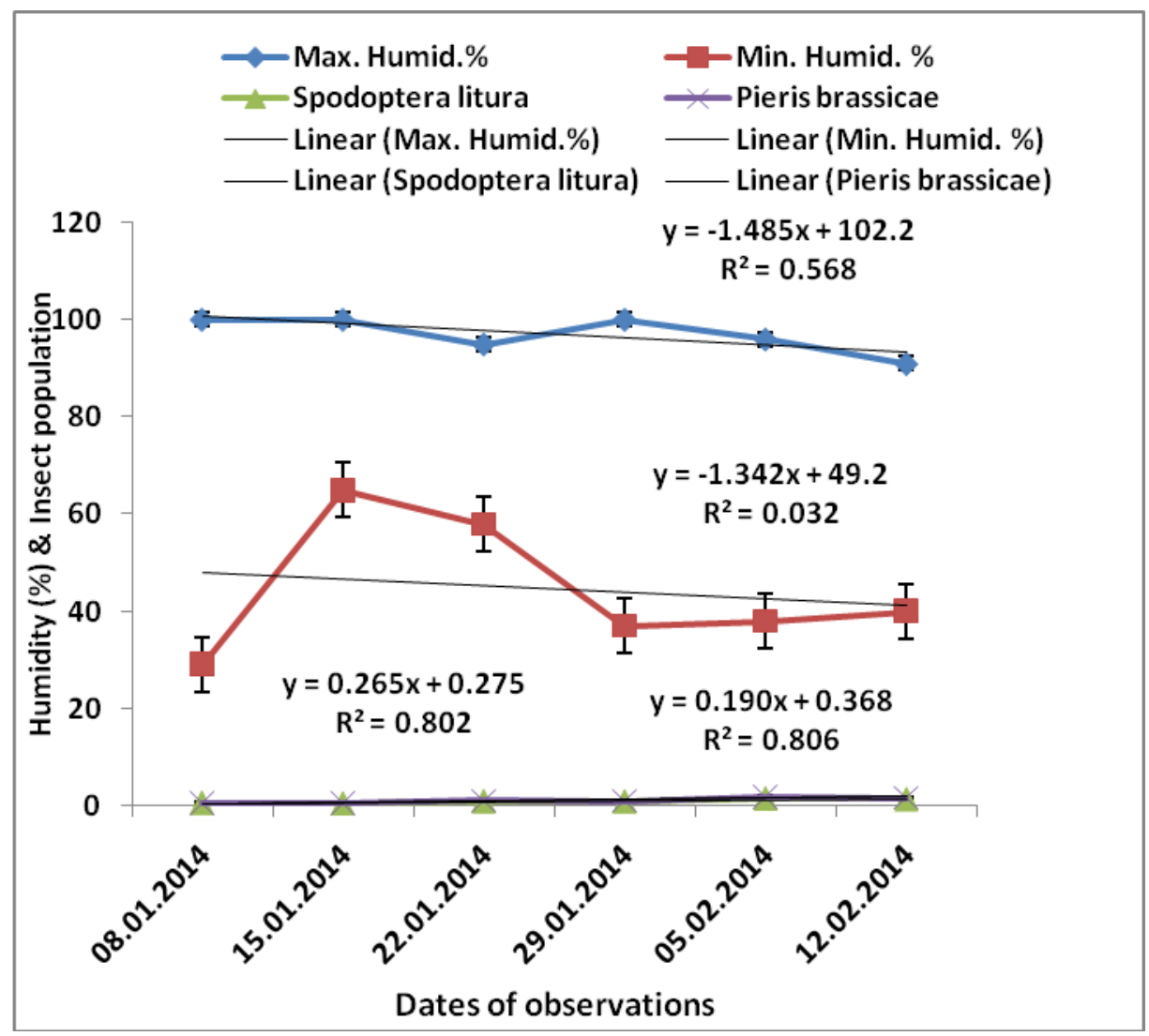

Figure 2. Trend of incidence of Spodoptera litura and Pieris brassicae on cabbage at different dates of observations as influenced by maximum and minimum humidity

\section{Relationship of Spodoptera litura population with weather factors}

There was a strong positive correlation $(\mathrm{r}=0.824$ and $\mathrm{r}=0.920)$ between population of Spodoptera litura and temperature (maximum and minimum) presented in figure $3(\mathrm{~A} \& \mathrm{~B})$. It indicates that the population of $S$. litura increases with increasing of both maximum and minimum temperatures. The contribution of the regression $\left(R^{2}=0.679\right.$ and $\left.R^{2}=0.847\right)$ was $68 \%$ and $85 \%$, respectively. On the other hand, there was a negative correlation $(r=-0.439)$ between population of $S$. litura and maximum relative humidity. However, a strong negative correlation $(r=-0.716)$ between population of $S$. litura and minimum relative humidity (Figure 3, C\&D). Likewise, the contribution of the regression $\left(\mathrm{R}^{2}=0.193\right.$ and $\left.\mathrm{R}^{2}=0.513\right)$ was $19 \%$ and $51 \%$, respectively (Figure 3 ). 

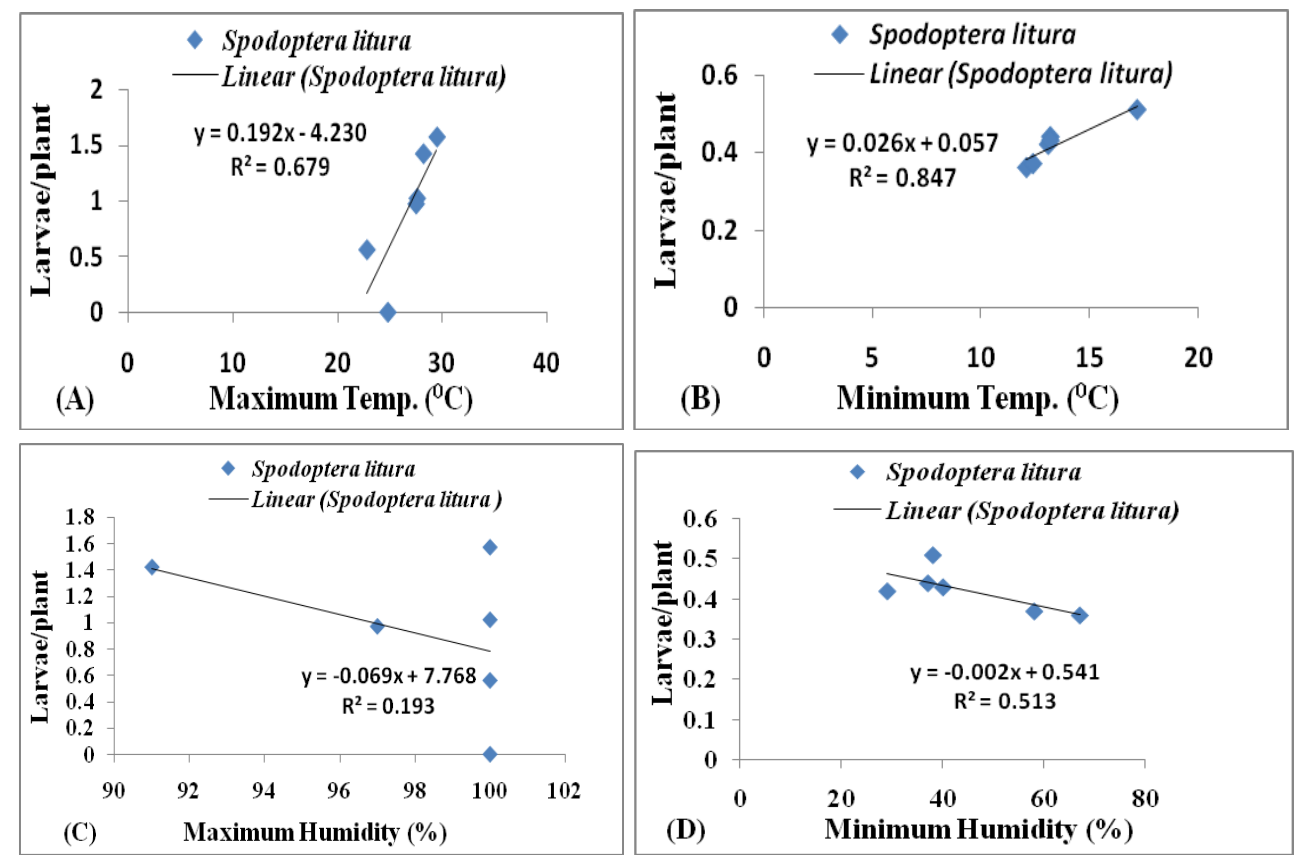

Figure 3. Relationship between Spodoptera litura population with (A) maximum temperature $\left({ }^{0} \mathrm{C}\right),(\mathrm{B})$ minimum temperature $\left({ }^{0} \mathrm{C}\right),(\mathrm{C})$ maximum humidity $(\%)$ and minimum humidity $(\%)$ in cabbage

\section{Relationship between Pieris brassicae population with weather factors}

The population of Pieris brassicae was positively correlated $(r=0.899$ and $r=$ 0.956) with maximum and minimum temperatures (Figure $4, A \& B$ ). The relationship indicated that the maximum and minimum temperatures had strong influence on the population of $P$. brassicae. The relationship can be expressed as $81 \%\left(\mathrm{R}^{2}=0.809\right)$ and $91 \%\left(R^{2}=0.913\right)$, respectively by the contribution of regression. On the other hand, there was a negative correlation $(\mathrm{r}=-0.443)$ between population of $P$. brassicae and maximum relative humidity and a strong negative correlation $(\mathrm{r}=$ 0.645 ) between population of $P$. brassicae and minimum relative humidity (Figure 4, $\mathrm{C} \& \mathrm{D})$. Likewise, the contribution of the regression $\left(\mathrm{R}^{2}=0.196\right.$ and $\left.\mathrm{R}^{2}=0.421\right)$ was $20 \%$ and $42 \%$, respectively (Figure 4 ).

Hemchandra and Singh (2007) reported that higher temperature, lower relative humidity, lower total rainfall, longer duration of sunshine hours and higher wind speed seem to favour the pest population build up. Patait et al. (2008) found that the population of Crocidolomia binotalis [C. pavonana], Hellula undalis, Plutella xylostella and Spodoptera litura on cabbage varied from 3.8 to 44.0, 1.0 to 6.2, 0.6 to 1.6 and 0.6 to 3.2 and 1.0 to $5.0,1.0$ to $1.6,1.6$ to 20.4 and 0.2 to 1.0 larvae/quadrat 
during rainy and winter seasons of 2006-07 in Latur, Maharashtra, India, respectively. The population of $H$. undalis and $S$. litura was affected positively by the action of minimum temperature and rainy days and negatively by forenoon relative humidity and rainfall (Patait et al., 2008). They also reported that the population of $S$. litura was influenced positively by forenoon relative humidity and negatively by minimum temperature and afternoon relative humidity. The findings of Patait et al. (2008) is slightly contradict with the findings of the present study.
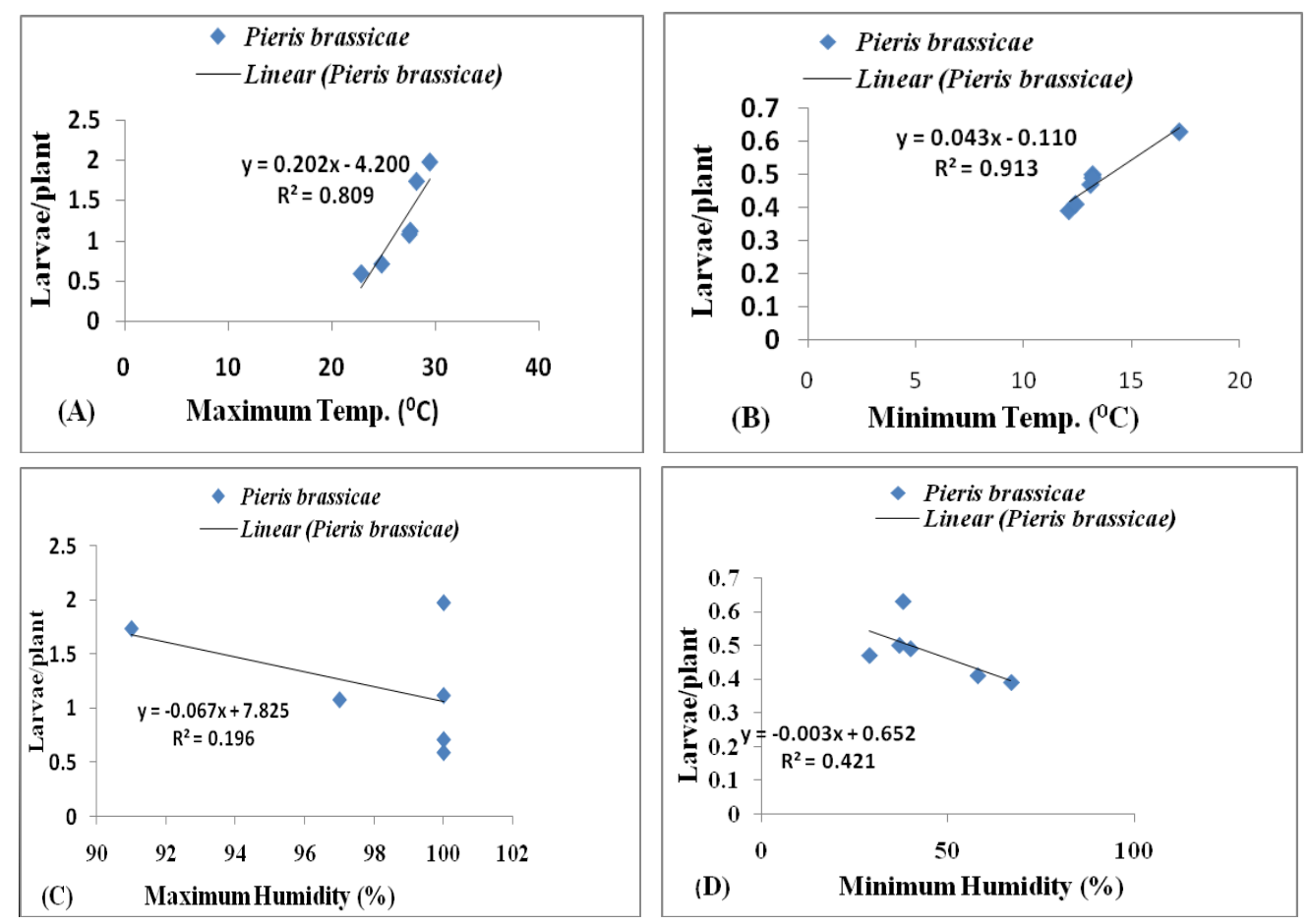

Figure 4. Relationship between Pieris brassicae population with (A) maximum temperature $\left({ }^{0} \mathrm{C}\right)$, (B) minimum temperature $\left({ }^{0} \mathrm{C}\right)$, (C) maximum humidity $(\%)$ and minimum humidity $(\%)$ in cabbage

Patra et al. (2012) reported negative influence of temperature; relative humidity and rainfall on population build up of aphid at Meghalaya condition. Both maximum and minimum temperature had major role to build up the population of diamond back moth, $C$. plutellae and coccinellids beetle while aphid population was enhanced only by maximum temperature (Patra et al., 2013). Vanlaldiki et al. (2013) found that the larvae of diamondback moth first appeared at the end of January $(0.20$ and 0.15 /plant), increased gradually and reached its peak by the end of March with a population (12.05 and 11.20/plant) during the two seasons respectively. The larval population declined (2.20 and 0.60/ plant) by the second week of April in both the 
years. The correlation studies indicated a significant positive correlation between larval population of diamondback moth and maximum and minimum temperature with an exception to the second year while maximum temperature showed a nonsignificant interaction. During 2009-10, the relative humidity (R.H), total rainfall and bright sunshine hours (BSSH) had negative correlation, whereas in the second year (2010-2011), R.H and rainfall had positive relation with the larval population of diamondback moth. There was a marked variation of diamondback moth incidence in different dates of planting. The result showed that early planted crop (15 November) harbored least number of the target pest (0.06/plant) with highest yield $\left(20.80 \mathrm{t} \mathrm{ha}^{-1}\right)$ whereas late planting (14 January) resulted in highest population (3.37/plant) with the lowest yield of $6.15 \mathrm{t} \mathrm{ha}^{-1}$ and devoid of any marketable heads. Bana et al. (2012) reported that the maximum and minimum temperatures showed significant negative correlation with aphid and larval population of diamondback moth, whereas, relative humidity and sunshine hours showed non-significant correlation. Ahmed and Ansari (2010) found that temperature and humidity recorded maximum and minimum i.e., $24.15^{\circ}$ to $32.91^{\circ} \mathrm{C}$ and 68.60 to 91.30 percent, respectively. Population build up is usually observed in II to IV week of September. Cotesia plutellae was found to be a dominant larval parasitoid while, Oomyzus sokolowskii parasitized relatively few pupae of $P$. xylostella. $34.77^{\circ} \mathrm{C}$ significantly $(\mathrm{p}<0.01)$ enhanced the population of DBM also on 8 September, 8 October, 2004 and 26 January, 2005. Rainfall negatively affected the DBM population in 2004-2005 and 2005-2006. Venkateswarlu et al. (2011) reported that among different abiotic factors, maximum and minimum temperature had significant positive correlation whereas morning and evening relative humidity showed significant negative correlation with DBM population. Sarkar et al. (2007) reported that DBM was the most abundant during January-February when the maximum and minimum temperature varied from 21.1 to $31.40 \mathrm{C}$ and 7.9 to $19.90 \mathrm{C}$, respectively on yellow sarson under West Bengal condition.

\section{CONCLUSION}

The highest peak populations of Spodoptera litura and Pieris brassicae were found on 5 February 2014 at $29.5{ }^{\circ} \mathrm{C}$ temperature and at $96 \%$ relative humidity. Temperature had positive influence on populations of both species while humidity had negative influence on them.

\section{REFERENCES}

Ahmad, T. and Answari, M.S. 2010. Studies on seasonal abundance of diamondback moth Plutella xylostella (Lepidoptera: Yponomeutidae) on cauliflower crop. Journal of plant Protection Research, 50 (3): 280-287

Anonymous. 2013. Research Report 2012-2013. Division of Entomology. Bangladesh Agricultural Research Institute, Gazipur-1701. pp. 87-98 
Bana, J.K., Jat, B.L. and Bajya, D.R. 2012. Seasonal incidence of major pests of cabbage and their natural enemies. Indian Journal of Entomology, 74 (3): 236-240

BBS, 2014. Staistical Pocket Book Bangladesh, Bangladesh Bureau of Statistics. Statistics Division, Ministry of Planning, Government of the People's Republic of Bangladesh, Dhaka. pp. 384

Hasan, F. and Ansari, M.S. 2011. Effects of different brassicaceous host plants on the fitness of Pieris brassicae (L.). Journal of Crop Protection, 30(7): 854-862

Hemchandra, O. and Singh, T.K. 2007. Population dynamics of DBM, Plutella xylostella (L.) on cabbage agro-ecosystem in Manipur. Indian Journal of Entomology, 69:154-61

Kumar, P., Prasad, C.S. and Tiwari, G.N. 2007. Population intensity of insect pests of cabbage in relation to weather parameters. Annals of Plant Protection Sciences, 15: 245-246.

Mahla, R.S., Singh, S. and Chaudhary, P. 2005. Management of diamondback moth, Plutella xylostella (L.) larvae by entomopathogenic fungus, Metarhizium anisopliae. Indian Journal of Entomology, 67: 342-344

Patait, D.D., Shetgar, S.S., Subhan, S., Badgujar, A.G. and Dhurgude, S.S. 2008. Seasonal abundance of Lepidopteran pests infesting cabbage in relation to weather parameters. Indian Journal of Entomology, 70 (3): 255-258

Patra, S., Thakur, N.S.A., Saikia, K. and Firake, D.M. 2012 Popu-lation dynamics of cabbage aphid, Bre-vicoryne brassicae L. on major cole crops in Meghalaya. Madras Agricultural Journal, 99:573-75

Patra, S., Dhote, V.W., Alam, S.K.F., Das, B.C., Chatterjee, M.L. and Samanta, A. 2013. Population dynamics of major insect pests and their natural enemies on cabbage under new alluvial zone of West Bengal. The Journal of Plant Protection Sciences, 5(1): 42 49

Rao, S.R.K. and Lal, O.P. 2005. Seasonal incidence of mustard aphid, Lipaphis erysimi (Kalt) and diamondback moth, Plutella xylostella (L.) on cabbage. Journal of Insect Science, 18(2): 106-110

Sarkar, A., Konar, A., Hazra, S. and Choudhuri, S. 2007 Inci-dence pattern and chemical control of dia-mond back moth, Plutella xylostella L. and mustard saw fly, Athalia lugens proxima (Klug.) infesting yellow sarson. Journal of Plant Protection and Environment, 4: 6-13

Uddin, M.N., Hoque, M.M., Hossain, S.M.M., Alam, S.N., Mollik, A.K.M.S.R., Khorsheduzzaman, A.K.M., Alam, S, Rahman, M.M., Karim, A.N.M.R., Rajotte, E. G. and Luther, G. C.2007. IPM approach for controlling two lepidopteran pests of cabbage in Bangladesh. Bangladesh Journal of Entomology, 17(1): 19-29

Vanlaldiki, H., Premjit, M. and Lalrinsanga, R. 2013. Effect of staggared planting on the seasonal abundance of diamondback moth (Plutella xylostella Linn) on cabbage under North Eastern hill zone, Imphal. The Bioscan, 8(4): 1211-1215

Venkateswarlu, V., Sharma, R.K., Chander, S. and Singh, S.D. 2011 Population dynamics of major insect pests and their natural enemies in cabbage. Annals of Plant Protection Sciences, 19: 272-77 